This item was submitted to Loughborough's Institutional Repository (https://dspace.lboro.ac.uk/) by the author and is made available under the following Creative Commons Licence conditions.

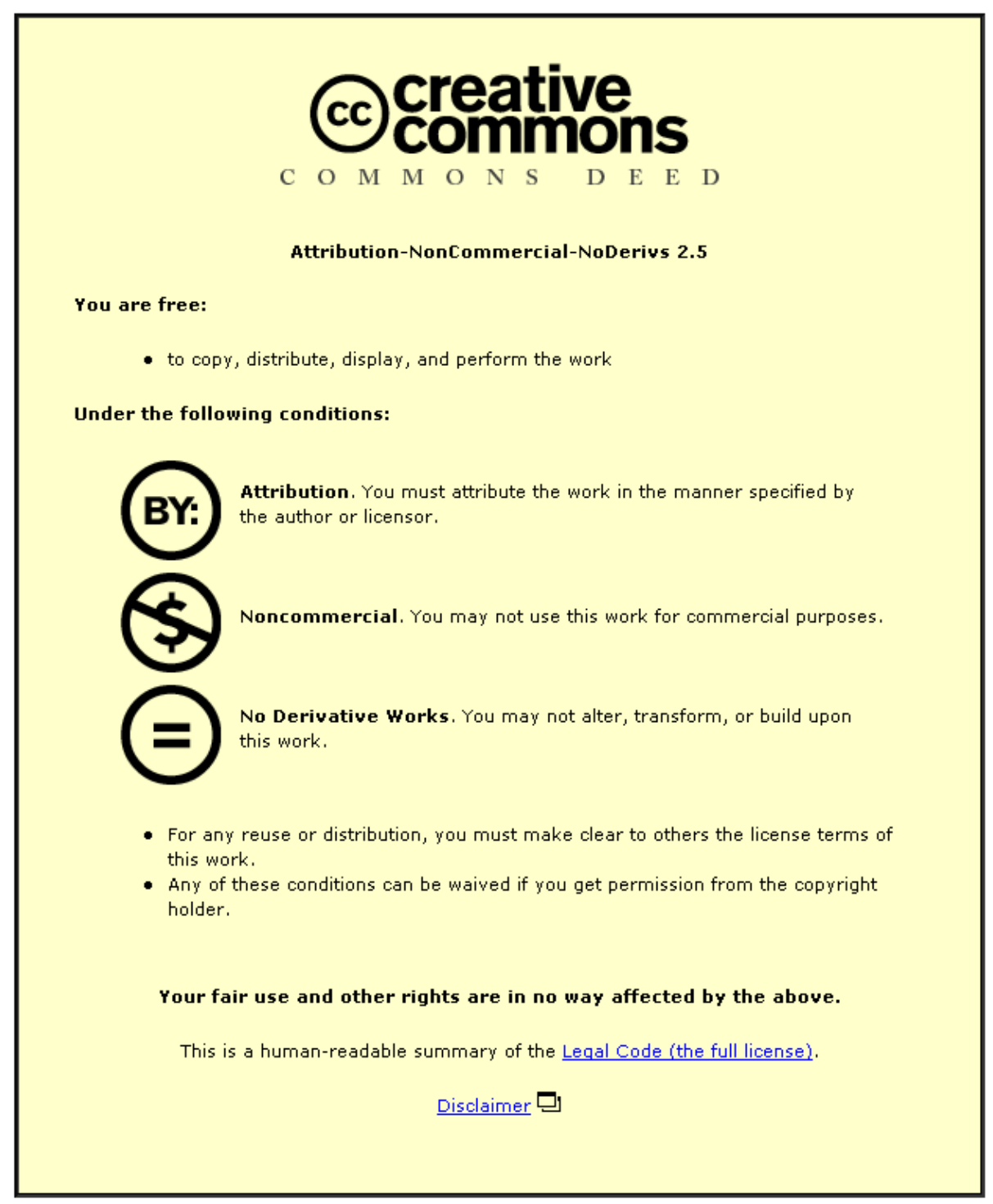

For the full text of this licence, please go to: http://creativecommons.org/licenses/by-nc-nd/2.5/ 


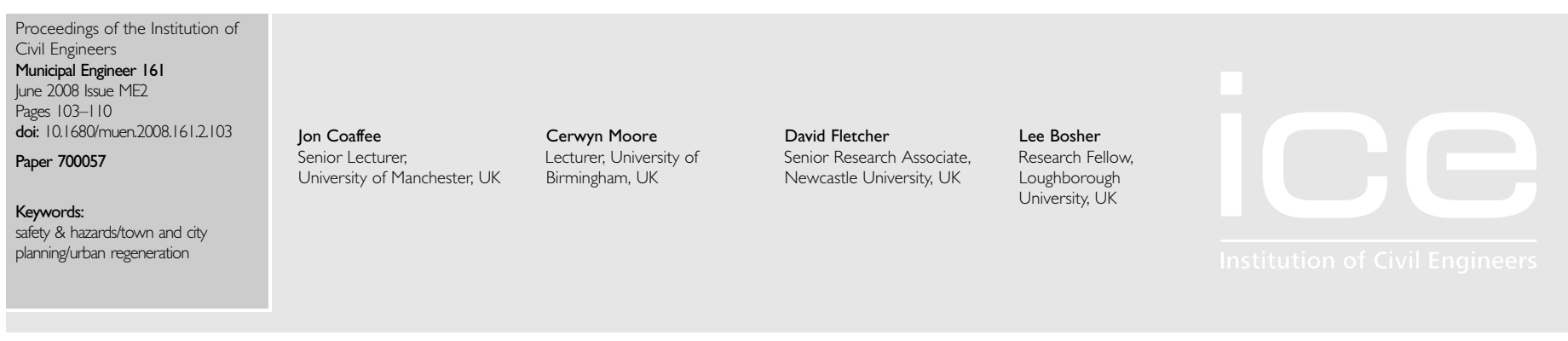

\title{
Resilient design for community safety and terror-resistant cities
}

\author{
J. Coaffee PhD, C. Moore PhD, D. Fletcher PhD and L. Bosher PhD, FRGS, MICDDS
}

\begin{abstract}
Resilience against an array of traditional and unconventional terrorist threats is increasingly important to the way towns and cities are designed and managed and how built environment professionals attempt to enhance levels of community safety. This is particularly the case with regard to crowded public places and transport systems such as light rail or trams, which are seen as particularly vulnerable to terrorist attack. This paper argues that contemporary terrorist threats and tactics mean that counter-terrorism in urban areas should increasingly seek to hybridise hard and soft engineering solutions in order to design and manage the built environment in ways that can reduce the occurrence or impact of a terrorist attack. In particular, it is argued that for counter-terrorism to be successful, inter-professional solutions are required for a wide range of public, private and community stakeholders that are (or should be) involved with the planning, design, construction, operation and management of public places.
\end{abstract}

\section{INTRODUCTION}

Successful places are safe, well maintained and well managed. Achieving this depends on managing the physical asset effectively and appropriately. With the right structures, people who live and use the place will be able to influence what happens there. ${ }^{1}$

Community safety is a broad issue that has become central to recent UK Government attempts to create sustainable communities and secure public places. For example, Safer Places: The Planning System and Crime Prevention argued that 'safety and security are essential to successful, sustainable communities'. ${ }^{2}$ Not only are such places well-designed, attractive environments in which to live and work, they are also places where freedom from crime-and from the fear of crime-improves the quality of life. This guide identified seven 'attributes of sustainability' that should be considered as 'prompts' to thinking about promoting community safety. ${ }^{2}$ These attributes,

summarised in Table 1, draw significantly on the ideas of "crime prevention through environmental design' and 'defensible space', which have been utilised by built environment professionals and law enforcement agencies since the 1970s.

Increasingly, these are also attributes that are entering current discourse on countering terrorism in urban areas, although such attempts to reduce terrorist risk are by no means unprecedented.
During the 1990s, the experience of UK authorities in attempting to 'design out' terrorism was largely confined to efforts to stop car bombing (or vehicle-borne improvised explosive devices (VBIEDs)) by the Provisional Irish Republican Army (PIRA) against the economic infrastructure in London. More recently, concerns about the likelihood and impact of terrorist attack on crowded public places using a variety of novel and experimental deployment methods (e.g. the failed attacks in central London and a partially successful VBIED at Glasgow airport in 2007) has heightened the sense of fear in many urban locations as future attacks against 'soft targets' appear more likely. Such forms of terrorist attack also have echoes of a spate of PIRA bombings in the mid-1970s against soft targets such as pubs and restaurants.

In short, over the last five years, the threat of terrorism has evolved rapidly; new approaches to countering terrorism are needed in response. Terrorism is understood here to mean one of many operational methods deployed either singularly or as part of a campaign so as to affect one or more targets, thereby affecting political, social and economic life. ${ }^{3}$

Crowded public places (e.g. shopping areas, transport systems, sports and conference arenas) in particular are at high risk. Furthermore, they cannot be subject to traditional security approaches such as searches and checkpoints without radically changing public experience. The creation of an environment that is inherently more resilient and less likely to suffer attack through 'designing in' counter-terrorism to physical and managerial urban systems, offers hope of improving security in an acceptable as well as effective way.

Within this context, this paper sets out the challenges for municipal engineers, built environment professionals and security agencies to increase the terror resistance of our cities through physical intervention and managerial measures-the hardware and software of 'resilient planning, ${ }^{4}$ The approaches described form the basis of ongoing research by the authors (Fig. 1).

\section{WHY RESILIENT DESIGN FOR PUBLIC PLACES?}

Before the events of $9 / 11$, threats of terrorism predominantly came from VBIEDs targeting major financial or political centres. In response, attempts to counter terrorism often utilised planning regulations and advanced technology to create 'security zones' or 'rings of steel' where access was restricted and surveillance significantly enhanced. ${ }^{5}$ 9/11 made such counterterrorist tactics appear inadequate, and security policy began to 


\begin{tabular}{|ll|}
\hline Attribute & Descriptor \\
\hline Access and movement & Places with well-defined routes, spaces and entrances that provide for convenient movement \\
& without compromising security \\
Structure & Places that are structured so that different uses do not cause conflict \\
Surveillance & Places where all publicly accessible spaces are overlooked \\
Ownership & Places that promote a sense of ownership, respect, territorial responsibility and community \\
Physical protection & Places that include necessary, well-designed security features \\
Activity & Places where the level of human activity is appropriate to the location and creates a reduced risk of \\
Management and maintenance & crime and a sense of safety at all times \\
& $\begin{array}{l}\text { Places that are designed with management and maintenance in mind, to discourage crime in the } \\
\text { present and the future }\end{array}$ \\
\hline Table I. Attributes of sustainability relevant to crime prevention and community safety
\end{tabular}

shift to proactive and pre-emptive solutions based on ideas of resilience-defined here as "the ability to detect, prevent and if necessary handle disruptive challenges...This includes but is not limited to disruptive challenges arising from the possibility of a terrorist attack'. ${ }^{6}$ This has forced a rethinking of traditional emergency planning and counter-terrorist tactics given the increased magnitude of the threats faced-especially those from chemical, biological, radiological and nuclear (CBRN) sources which many terrorist groups have expressed significant interest in utilising in attacks, and which, in the words of the UK prime minister, could hit 'anywhere and from any place'. ${ }^{7}$ Equally, however, the threat posed by person-borne explosive devices in crowded public places (e.g. the Bali pub bombings in 2002 and the Madrid train attacks in 2004) is setting new challenges for professionals involved in providing security in crowded places, especially in light of the suicide attacks on the London transport network in July 2005 and the London and Glasgow attacks in July 2007.

Although debates on the relationship between new and traditional threats continue, the methods and tactics adopted by terror groups are novel, innovative and increasingly focused on mass casualty strikes or multiple coordinated attacks. Such attacks, often conducted by suicide attackers and tactically aimed at 'soft' targets and more generally crowded places, have led to considerable ongoing and multi-disciplinary research. ${ }^{8}$ Crowded areas have features in common (such as their lack of access control), but may be bounded (e.g. a stadium or train) or unbounded (e.g. a shopping area). Some policy-related work has helped to understand the changing nature of the threat in relation to evolving groups such as $\mathrm{Al}$ Qaeda. ${ }^{9}$ Nevertheless, much of the academic work post-9/11 fails to offer the truly multi-

disciplinary and inter-professional approach needed to develop strategies to maintain community safety by deterring terrorism in public places while ensuring public acceptability of the security measures.

While iconic buildings and specific hubs such as airports have long been identified as targets for terror attacks, a more general reading of public places is also required if resilience is to be enhanced. For example, public places such as shopping centres, pubs, clubs and markets may be especially crowded at specific times of the day or year. Depending on their social and cultural function, public places may be fixed, but they may also be

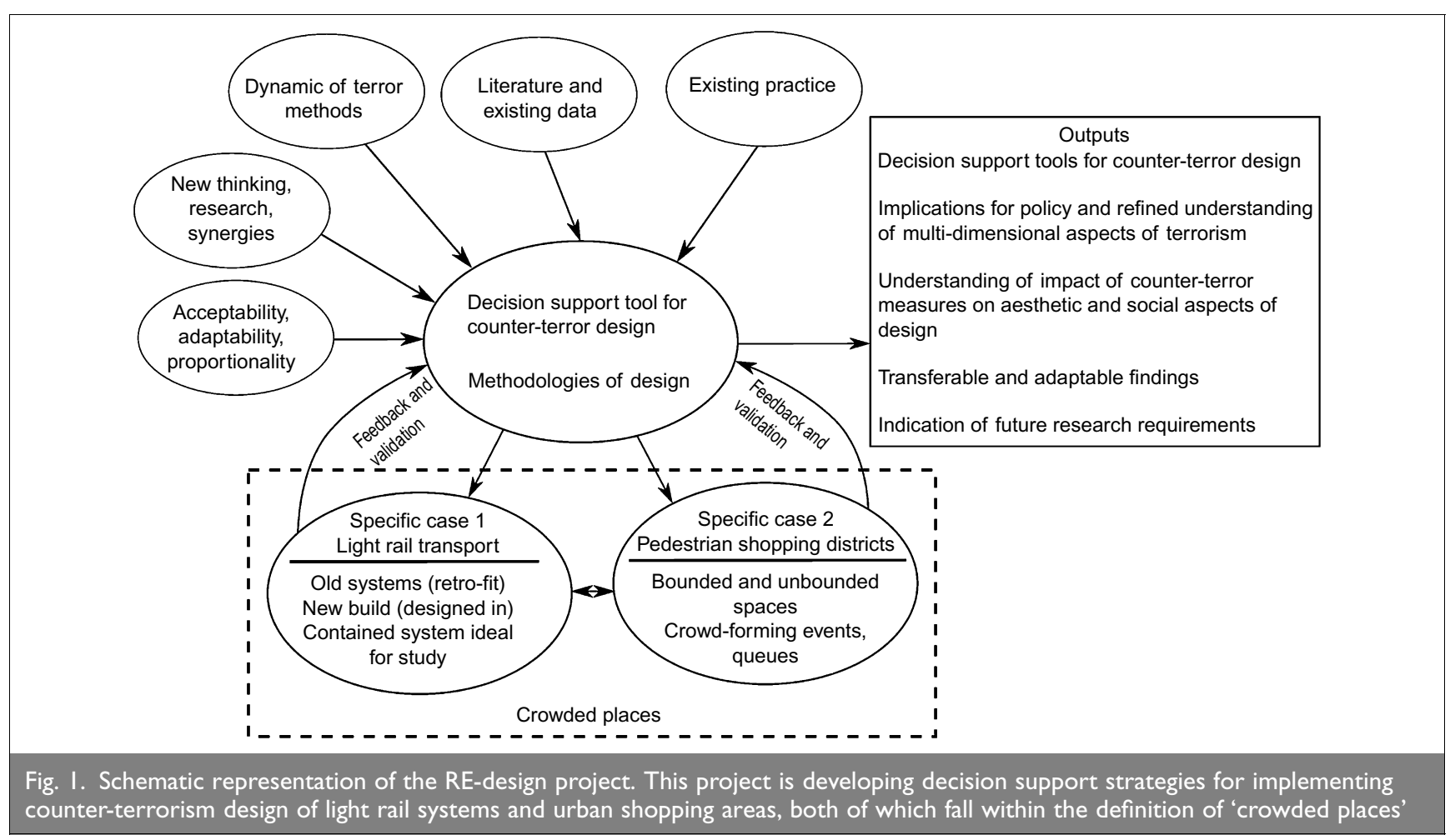


cordoned-off due to events and subject to impromptu queuing and crowding. Although public places such as shopping malls or train stations serve a community, they may be simultaneously linked to the private sector, and accordingly, they could be crowded at peak shopping or travel times. Together, this blend of changing terror methods and targets, especially those directed at crowded places in urban centres, provides a challenge for security professionals and practitioners.

National policy makers and the security services now perceive attacks against crowded public places as one of their key priorities in the ongoing fight against terrorism. Since early 2003, the UK has had a long-term strategy for developing resilience for counterterrorism (known within the government as Contest). Its aim is to reduce the risk of terrorism in order that people can go about their daily lives freely and with confidence. This resilience strategy is divided into four strands: prevent, pursue, protect and prepare. ${ }^{10} \mathrm{In}$ this context, counter-terrorism design within the urban environment can both reduce the likelihood of a place being attacked and assist in the response stages if an attack occurs (Fig. 2).

The protect strands of Contest are of key concern for issues of community safety. For example, the Centre for the Protection of National Infrastructure (CPNI) argues that

'the Protect strand is concerned with reducing the vulnerability of the UK and UK interests overseas to a terrorist attack... (and that) this covers a range of issues including:

protecting key utilities by working with the private sector; strengthening border security, so that terrorists and those who inspire them can be prevented from travelling here and we can get better intelligence about suspects who travel, including improving our identity management;

reducing the risk and impact of attacks on the transport system through security and technological advances;

protecting people going about their daily lives in crowded places'. ${ }^{11}$

Likewise, the prepare strand on Contest is of vital concern in enhancing what might be termed 'bouncebackability' from terrorism. ${ }^{4}$ A useful way to understand how risk can be reduced is to consider risk as the product of vulnerability (how susceptible a place or system is to attack), threat (how likely is the occurrence of an attack, how motivated people are to attack) and criticality (how serious the consequences are). ${ }^{12}$ This helps break down the somewhat overwhelming aim of reducing the risk of a terrorist

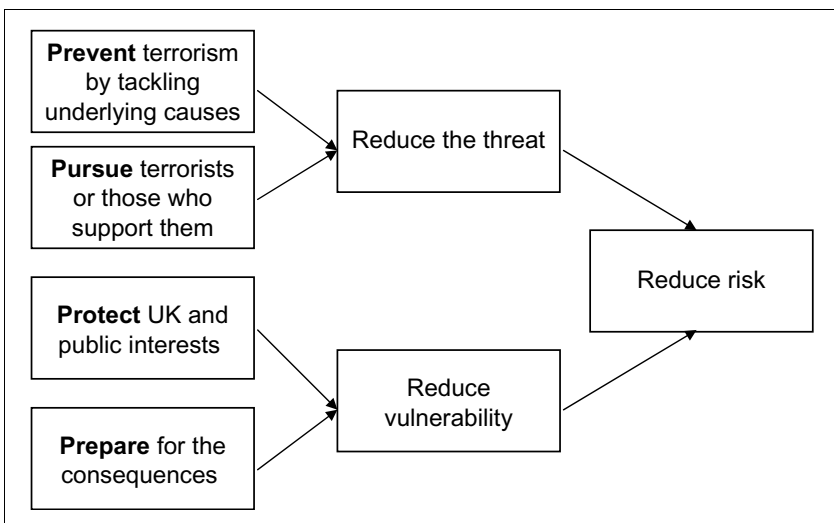

Fig. 2. Representation of the UK government's Contest strategy attack by showing that risk can be reduced if any one of these factors can be minimised. In many urban settings such as shopping areas or light rail rapid-transit systems it may be difficult to reduce vulnerability (because the areas are open to the public and searching those entering is not a viable or acceptable option) or threat (largely outside the influence of a municipal engineer or transport operator). However, addressing the consequences of an attack to enable the system or space to 'bounceback' into normal operation is more readily achievable. Effectively, if the consequences of an attack are few, conducting the attack may become less attractive, and the risk could thereby be reduced.

\section{RECENT THREATS TO PUBLIC PLACES IN THE UK}

Recent evidence in the UK highlights that the threat posed by terrorists targeting public places is real. For instance, the unsuccessful coordinated improvised car bomb attacks in central London in June 2007 demonstrated the need to defend crowded public places. In this case, a car bomb was planted in central London outside the popular nightclub Tiger Tiger. The car, packed with $60 \mathrm{l}$ of petrol, gas cylinders and nails, was parked near Piccadilly Circus. Earlier the same night, a device only $170 \mathrm{~m}$ away had been removed and impounded by traffic wardens from a nearby street. Both bombs were poorly constructed and fortunately failed to explode. This failed attack and the improvised attack the following day when a blazing car was driven into Glasgow airport's terminal building led to a reassessment by government counter-terrorism security advisors of other public venues with a view to providing additional protection. As UK prime minister Gordon Brown noted in a 'statement on security' (25 July 2007):

The protection and resilience of our major infrastructure and crowded places requires continuous vigilance. I can confirm that over 900 shopping centres, sports stadiums and venues where people congregate have been assessed by counter-terrorism security advisers and over 10000 premises given updated security advice. ${ }^{13}$

Concern is also being expressed about management of the security threat, in particular security procedures and queuing at airports ${ }^{14}$ and other events at which rigorous security checks are in force. These queues may themselves become targets since they are outside secure areas and could be easily attacked. Enhancing community safety in crowded places has been backed up by large and ongoing streams of work being conducted by the National Counter Terrorism Security Office (Nactso) on disseminating protective security advice to places deemed vulnerable to targeting (e.g. shopping centres, bars, pubs, clubs and sports stadia.) ${ }^{15}$ This concern for the protection of crowded places was further reinforced in Lord West's report (published in November 2007 following the London and Glasgow attacks), which called for counter-terrorism measures to be embedded within the design, planning and construction of public places. ${ }^{16}$

Traditionally considered separately from the crowded spaces for which Nactso has primary responsibility, transport systems are hugely important in the vitality of urban life and the economic success of urban areas. Light rail systems interface most closely with city centre environments, either through on-street running or underground stations opening onto city streets. The lead on the security of such systems is being taken by the Department 
for Transport's (DfT) Transport Security and Contingencies Directorate (Transec) and by the British Transport Police. Since there are many fewer underground and light rail facilities than other urban crowded places such as shops and bars, security advice can be far more specific. There is a regulatory security regime in place for London Underground, Docklands Light Railway and Glasgow Subway, with the DfT acting as inspector and regulator and day-to-day delivery of security resting with the system operators in partnership with British Transport Police. Other light rail operators are subject to an advisory best practice security programme, ${ }^{17}$ although legislation exists that can move this to a regulatory footing if the need arises. Despite the different regulatory approaches, the new threats faced by these systems are similar to those faced by other crowded places, and their normal operation precludes security approaches such as airport-style perimeter searches.

\section{BEYOND ENGINEERED DEFENCE}

To achieve the creation or construction of a resilient environment and to reduce the risk of a wide and unpredictable variety of terrorist threats requires an adaptable and holistic security effort that encompasses both 'hard' engineering and design solutions, and 'soft' governance and management arrangements. As Richard Little ${ }^{18}$ noted

Threats are unpredictable and the full range of threats probably unknowable... Security in this situation needs to be flexible and agile and capable of addressing new threats as they emerge. Protective technologies have a key role to play in making our cities safer but only if supported by organizations and people who can develop preattack security strategies, manage the response to an attack, and hasten recovery from it.

Although there is much talk of new threats and changing terrorist tactics, we should also be aware that traditional methods of urban terrorism using VBIEDs are still likely to be more prevalent than CBRN or suicide attack. In this situation we should therefore seek to reinforce traditional counter-terrorism measures as well as planning for 'new' threat realities.

In response to new and evolving threats, new counter-measures have been required that often focus on worst-case recovery scenarios; this represents a shift in emphasis from previous reactive emergency planning philosophies. Such alterations in traditional strategies have led not only to the enhancement and reconceptualisation of approaches to counter-terrorism, but also to the requirement for a more robust decision support framework by which security processes can be effectively applied and managed in relation to the built environment. ${ }^{19}$

One security approach is to attempt to 'design out' or mitigate the effects of terrorism by creating an environment that is inherently less likely to suffer attack or can minimise consequences and impact-one in which primary security resources such as the police can operate without hindrance by building layout or one in which public participation in counter-terrorism through general vigilance is enhanced. Similar approaches have been used successfully to design out crime in residential environments ${ }^{20}$ and transport infrastructure. ${ }^{21}$ A considerable body of work already exists on environmental design for crime prevention where a sense of community safety can be fostered by enhancing defensible space, natural surveillance and community

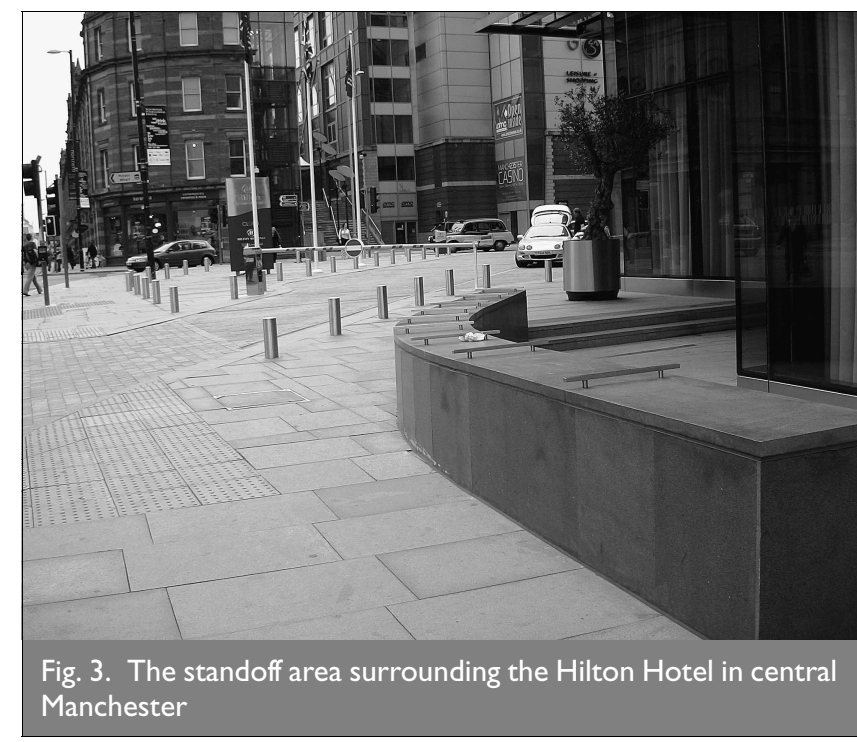

interaction. ${ }^{22}$ In some cases this could crossover to provide counter-terrorism strategies.

From an engineering design perspective, the use of 'hardened' or enhanced-performance materials (e.g. those offering blast or fragmentation resistance) has been increasing. Such proactive strategies emerged in the 1990s in London as a response to PIRA attacks against the City of London and London Docklands, but have been increasingly mainstreamed across the country and utilised by the police and built environment professionals; Davey et al., for example, highlight the greater use made of blastresistant materials and structures in building design. ${ }^{23}$ The adoption of such solutions in some areas of the UK now plays a part in successful planning approval for new projects. From an urban design perspective, the construction of spaces that allow for clear sightlines for CCTV, greater 'standoff' distances around buildings or controlled access in certain areas has been encouraged. For example, following the 1996 bomb in central Manchester, damaged areas of the city centre were reconstructed with community safety in mind through restricted vehicle access to central shopping zones, a centralised CCTV system, secure 'standoff' areas for high-profile (and hence high target risk) buildings and bomb-proof litter bins (Fig. 3).

Urban transport systems commonly adopt many of the same measures in their design and operation of stations, with most measures focused on preventing concealment of an explosive device. For example, ticketing and vending machines can be positioned to avoid gaps in which a device could be hidden. Bicycle racks and left luggage lockers present particular difficulties, and in many cases have been simply removed or positioned some distance from the main station facilities. However, these actions can do little to defend against a personborne explosive device; design solutions such as blast-resistant glazing may offer the hope of minimum damage and quick recovery in the worst case. High-technology sensors for early detection of explosive or chemical agents may also have a role, ${ }^{24}$ although mass scanning of high volumes of people remains technologically challenging.

With many new security measures being introduced in a variety of crowded public places, there are pitfalls and difficulties in the adoption of approaches originally developed for non-terror 
situations (crime reduction and deterrence) for counter-terrorism. For example, a terrorist and a criminal may have different psychological relationships to the risk of being caught, which will affect the success of counter measures. In addition, crime almost always has measurable social and financial costs, whereas there is currently no economic measure for the threat of terrorism. Terrorist threats are not easily quantified, so it is difficult to determine the 'right' level of security, especially for organisations that are too small to justify dedicated security professionals.

An additional factor is the reverse process whereby counterterrorism strategies and technologies may be re-appropriated for crime-reduction purposes. ${ }^{25}$ For example, sniffer dogs introduced to detect a terrorist threat or the installation of advanced CCTV may in reality be used for crime deterrence. While this may be a valuable additional role, the change in public perception of the counter-terrorism measures could lead to a weakening in the resilience of a place or system when threatened or attacked. ${ }^{26}$ A parallel issue, which raises public acceptability questions, is 'function creep' in the use of personal data from smart card ticketing systems such as London's Oyster card. ${ }^{27}$ Data originally used for transport planning are increasingly being accessed during police inquiries, ${ }^{28}$ although there is no bulk access to data by police, public sector or commercial organisations. ${ }^{29}$

Spatial design, material choices, aesthetics and many other 'design' factors can influence a location's vulnerability to attack. It is not suggested that design is a primary defence against a terror attack, but it does form one part of a multi-layered and multi-pronged system of security. Current research has identified that key stakeholders recognise that resilient design will become central to planning, construction guidelines and legislation in the near future. ${ }^{30}$ An important aspect of counter-terrorism design is that it can provide benefits at very low cost if it is implemented at the planning stage of a shopping area, rail system or venue, ${ }^{31}$ whereas costs can be much higher in a retro-fit situation. ${ }^{32}$ For example, this message was reinforced by Lord West's counterterrorism report, which emphasised how proactive engineering and management solutions to mitigate the impact of terrorism should be incorporated into pre-planning and design stages of new developments.

\section{BALANCING EFFECTIVENESS AND ACCEPTABILITY IN COUNTER-TERRORISM MANAGEMENT}

As highlighted earlier in this paper, the hard engineering component of resilient planning is only part of the counterterrorism scenario. Equally important is the governance solution developed to ensure that all relevant stakeholders are informed and consulted about the development of counter-terrorism measures and strategies. In short, the search for interprofessional solutions in resilient planning aims to facilitate a joined-up approach to development among the police, emergency planners, spatial planners and other built environment professionals through incorporating risk management into urban decision-making. ${ }^{30}$ Similar reforms have taken place in transport operations, with an increasingly regulatory approach for both national 'heavy' rail and urban light rail or metro systems, and the publication of a recommended best practice guide for bus and coach security. ${ }^{33}$

Development of this multi-level and inter-professional managerial nexus for resilience is still ongoing and has tended to be more concerned with developing statutory obligations than in broadening the inclusively of decision making. This is evident in both design decision making and in attempts to develop greater levels of community safety, alongside an appreciation of the potential social impacts of such measures.

\section{I. Integrated thinking on resilience}

There is no structured integration of views regarding resilient planning and design in contemporary cities among built environment professionals. ${ }^{19}$ Generally, issues of resilience in relation to security have tended to take a restricted and technocratic approach, applicable to only a narrow cohort of 'experts' most notably the police. ${ }^{4}$ Today there is undoubtedly a shift towards more integrated approaches to managing risk, one that requires more inclusive conversations with different stakeholders to develop a sense of collective responsibility. This is particularly the case with so much of city centres privately owned or managed, for example by shopping centres, and supported by independently run transport services. What is now required is security professionals to be involved in construction and planning from the outset, "mitigating these risks at the core of the buildings design, rather than being an afterthought'. ${ }^{34}$

The management of crowded places has also been subject to appraisal in order to assess how it might assist the counterterrorist effort. For the business community and public sector professionals across the UK, training schemes (which have emerged from London's experience of dealing with terrorism) are now being developed to help them plan for a possible attack and integrate their thinking in order to effectively deal with both traditional and 'new' forms of terrorist attack. These schemes have been rolled out across the UK in order to heighten community safety and the speed of response to potential terrorist attack as well as aid business continuity.

Such initiatives include project Griffin and project Argus. In 2004, the City of London Police and the Metropolitan Police launched project Griffin as a joint partnership with the private sector security industry. The underlying principles of Griffin were concerned with trying to disrupt hostile reconnaissance (i.e. would-be terrorists visiting potential attack sites in advance), aiming to provide cordon support and/or high-visibility patrols, and supporting police services during critical incidents. For example, on 7 July 2005 in the central financial zones of London, numerous Griffintrained private security guards assisted the police. At the time of writing, project Griffin has been implemented in a further 18 cities in the UK to raise awareness of counter-terrorism and law enforcement issues in order to better equip security personnel to deal with their organisation's security challenges on a day-to-day basis and in the event of a major incident.

Project Argus, a Nactso initiative started in 2007, has been influential across the UK in aiding business continuity; it explores ways to aid businesses in preventing, handling and recovering from a terrorist attack, particularly against crowded 
public places. To date over 200 Argus workshops have been held in towns and cities across the UK, providing an opportunity for local business to reflect upon their existing security and contingency plans, and take part in exercises that simulate a terrorist attack similar to the London bombings of July 2005. The aim of Argus is to build participants' capacity to react in the event of an attack.

\subsection{The acceptability of resilient design}

Current approaches to urban 'place-making' are now expected to take account of the multiple voices of stakeholders and local community-a long-standing difficulty for built environment professionals. ${ }^{35}$ Importantly, key issues related to the social impact of counter-terrorism strategies and community engagement have been largely absent from official discussions on resilience and counter-terrorism. It is argued that this is a key omission-for counter-terrorist resilient design to be successful it must not only be effective (incorporating the design and managerial solutions previously mentioned) but must also be acceptable to the owners, inhabitants and users of particular places. Furthermore, this acceptability encompasses complex financial, social and aesthetic considerations.

Recent scholarship in humanities, urban studies and architecture has highlighted the risks that counter-terrorism measures pose for the functional integrity of urban space in terms of their potential to contribute to an atmosphere of fear, ${ }^{36}$ a culture of surveillance, consequences for social control and freedom of movement, ${ }^{37}$ and a reduction in democratic involvement in urban planning and construction ${ }^{38}$ often leading to the increasing militarisation of urban design. ${ }^{39}$ There is also a particular risk that counter-terrorism measures may alienate specific members of the community who feel singled out as potential threats and, in extreme cases, could turn to more radical beliefs.

There is clearly a need to address the problem of terrorism while remaining attuned to social concerns through the integration of social factors. Such concerns are often difficult to quantify within the overly technocratic counter-terrorism design solutions that are commonplace in the engineering sciences. More practically, decision-makers must consider which strategies best support the maintenance of public vigilance-and which create unnecessary fear.

\section{THE EMERGING RESEARCH AGENDA: ENHANCING COMMUNITY SAFETY AND COUNTER- TERRORISM IN URBAN RENAISSANCE}

There is widespread concern for community safety amidst apprehension about terrorist attacks on crowded public placesin particular, security considerations for urban outdoor shopping areas and the more highly bounded, but still open access, light rail systems that support the busiest of city centres.

In pedestrian spaces, elements such as public squares, shopping promenades, outdoor cafés and restaurants are increasingly emphasised in urban planning and architectural design, and are important ingredients in contemporary urban renaissance. By design, they are open, flexible and rapidly evolving. They are a hybrid of commercial and public space that has been quick to incorporate developments in media-based architecture (media screens, light installations, information terminals, etc.), thereby offering the potential for new forms of public participation and interaction in the city and the possibility of an increasingly responsive built environment. ${ }^{40}$

Likewise, light rail systems are an essential component in many cities (particularly those undergoing regeneration) and offer hope of overcoming traffic congestion crises faced by many city centres. These systems are designed to be easy to access and high passenger flows demand a minimum of delays, making many conventional security approaches (such as those employed at airports) unfeasible. ${ }^{41}$ Both these types of 'crowded places' have great potential to benefit from design changes offering deterrence or protection from terrorism, but their essential role in modern cities means that security cannot be allowed to detract from their primary function. In other words, whatever design, engineering or management changes are implemented, they must be seen as proportional to the ongoing threat of terrorism. It is possible that aiming to reduce the consequences should an attack occur, rather than focusing solely on prevention, may achieve this. There will also be the inevitable need to incorporate retro-fit design solutions, especially as modes of terrorism change.

What is also constantly alluded to in the academic and policy literature is the need to balance higher levels of security with concerns for the functionality of places. As resilient planning and design continues to evolve, increasingly inter-professional solutions and an interdisciplinary perspective for evaluating counter-terrorist design (including social impact, physical feasibility and likely effectiveness of the designs) are required.

From a construction sector perspective, Bosher et al. ${ }^{42}$ argue that there are a number of key actions required to address systems in the built environment that are at risk from natural hazards (such as floods) and human-induced hazards (such as terrorist attacks). These actions are categorised as broadly relating to

(a) innovation and knowledge-transdisciplinary training and hazard awareness

(b) operations-information exchanges between a wide range of stakeholders such as planners, designers, engineers and the emergency and security services

(c) planning-well-designed and suitable locations

(d) legislation and regulatory incentives-building codes and good practice guidance.

Bosher et al. further establish the need for a framework to help construction and non-construction stakeholders to address hazards during the earliest planning and design stages. ${ }^{19}$ This, it is argued, can be achieved through the creation of decision support tools such as those that will be developed in the project outlined in Fig. 1. It is hoped that such tools will improve relationships between those who design and engineer public spaces, those that manage and secure them, and those that use them.

Counter-terrorism strategies and resilience in the UK will be increasingly successful when more fully integrated into the planning, design, construction, operation and management of public places and their support systems (e.g. transport networks). 
This will, of course, require the adoption of locally contingent solutions that are both effective and acceptable. Furthermore, any solutions will require an analysis of the material specificities (including symbolic and aesthetic implications) and management processes involved in decisions on counter-terrorism, alongside an assessment of the evolving threat profile and emerging tactics of would-be terrorists.

\section{ACKNOWLEDGEMENTS}

The research for this paper was supported by an Engineering and Physical Sciences Research Council grant (EP/F008635/1) entitled Resilient design (RE-Design) for counter-terrorism: decision support for designing effective and acceptable resilient places. Dr Joel McKim, now at Concordia University, Canada, contributed to the development of this project while at Goldsmiths College, London.

\section{REFERENCES}

1. English Partnerships. Urban Design Compendium 2 (UDC 2): Delivering Quality Places. English Partnerships and the Housing Corporation, London, 2007, p. 172.

2. Office for the Deputy Prime Minister. Safer Places: The Planning System and Crime Prevention. ODPM/Home Office, London, 2004.

3. CRenshaw M. The causes of terrorism. Comparative Politics, 1981, 13, No. 4, 379-399.

4. COAFFEe J. From counterterrorism to resilience. European Legacy, 2006, 1, No. 4, 389-403.

5. CoAffee J. Rings of steel, rings of concrete and rings of confidence: designing out terrorism in central London pre and post 9/11. International Journal of Urban and Regional Research, 2004, 28, No. 1, 201-211.

6. See http://www.ukresilience.info/ccs/aims/index.shtm.

7. See http://news.bbc.co.uk/1/hi/uk_poltics/7093752.stm.

8. SILKE A. (ed.). Research on Terrorism: Trends, Achievements, Failures. Frank Cass, London, 2004.

9. SAgEman M. Understanding Terror Networks. University of Philadelphia Press, Philadelphia, 2004.

10. Home Office. Countering International Terrorism: the UK's Strategy. HMSO, London, 2006.

11. See http://www.cpni.gov.uk/About/cpniContext.aspx.

12. RAY J. C. Risk-based prioritization of terrorist threat mitigation measures on bridges. ASCE Journal of Bridge Engineering, 2007, 12, No. 2, 140-146.

13. See http://www.number10.gov.uk/output/Page12675.asp.

14. Miцmo D. MPs fear danger in queues at airports. The Guardian, 2007, July 26, p. 10.

15. See http://www.nactso.gov.uk/crowdedplaces.php.

16. Thоmpson M. PM calls on architects to design out terror. See http://www.architectsjournal.co.uk/news/dailynews/ pm_calls_on_architects_to_design_out_terror.html for further details. Accessed 20/11/2007.

17. Department For Transport. Light Railway Security Recommended Good Practice. UK Transport Security and Contingencies Directorate (TRANSEC), London, 2007.

18. LITTLE R. Holistic strategy for urban security. Journal of Infrastructure Systems, 2004, 10, No. 2, 52-59.

19. Bosher L. S., Dainty A. R. J., Carrillo P. M. and Glass J. Builtin resilience to disasters: a pre-emptive approach. Engineering Construction and Architectural Management, 2007, 14, No. 5, 434-446.
20. Newman 0. Defensible Space: Crime Prevention through Urban Design. Macmillan, Basingstoke, 1973.

21. Stafford J. Safer travel by design: reducing crime on public transport. Proceedings of the Institution of Civil Engineers, Municipal Engineer, 2003, 156, No. 2, 87-88.

22. Cozens P. M. Sustainable urban development and crime prevention through environmental design for the British city: towards an effective urban environmentalism for the 21st Century. Cities, 2002, 19, No. 2, 129-137.

23. Davey C., Wooton and A. Hodge M. Designing against terrorism. Engineering Designer 2005, Jan.-Feb., 10-13.

24. Krebs M. D., Zapata A. M., Nazarov E. G., Miller R. A., Costa I. S., Sonenshein A. L. and DAVIS C. E. Detection of biological and chemical agents using differential mobility spectrometry (DMS) technology. IEEE Sensors Journal, 2005, 5, No. 4, 696-703.

25. Coaffee J. Terrorism, Risk and the City. Ashgate Publishing, Aldershot, 2003.

26. MarKs A. Drug detection dogs and the growth of olfactory surveillance: beyond the rule of law? Surveillance \& Society, Special Issue on Surveillance and Criminal Justice, Part 1, 2007, 4, No. 3, 257-271.

27. Blythe P. T. Improving public transport ticketing through smart cards. Proceedings of the Institution of Civil Engineers, Municipal Engineer, 2004, 157, No. 1, 47-54.

28. Murakami Wood D. (ed.). Report on the Surveillance Society, for the Information Commissioner by the Surveillance Studies Network. See http://www.ico.gov.uk for further details. Accessed 17/09/2007.

29. Transport for London Request Directory. Response letter to Freedom of Information Act request on Oyster card data sharing, 2006. See http://www.tfl.gov.uk/foi/5540.aspx for further details. Accessed 20/11/2007.

30. Bosher L. S., Dainty A. R. J., Carrillo P. M., Glass J. and Price A. D. F. Integrating disaster risk management into construction: A UK perspective. Building Research \& Information, 2007, 35, No. 2, 163-177.

31. VesILIND P. A. Engineering \& the threat of terrorism. Journal of Professional Issues in Engineering Education \& Practice, 2003, 129, No. 2, 70-74.

32. Clarke M. Terrorism, engineering $\&$ the environment. Terrorism \&t Political Violence, 2004, 16, No. 2, 294-304.

33. Department for Transport. Bus and Coach Security Recommended Best Practice. UK Transport Security and Contingencies Directorate (TRANSEC), London, 2005.

34. Dance S. Construction time again. See http://www.info4security.com/story.asp?sectioncode = 10 tstorycode $=3057545$ for further details. Accessed 20/11/2007.

35. Huskinson R. Involving the community in local government. Proceedings of the Institution of Civil Engineers, Municipal Engineer, 2001, 145, No. 2, 121-128.

36. Swanstrom T. Are fear and urbanism at war? Urban Affairs Review, 2002, 38, No. 1, 135-140.

37. Wolfendale J. Terrorism, security, \& the threat of counterterrorism. Studies in Conflict \& Terrorism, 2007, 30, No. 1, 75-92.

38. Marcuse P. and Van Kempen R. Of States and Cities: The Partitioning of Urban Space. Oxford University Press, Oxford, 2002.

39. Graham S. Cities, War and Terrorism: Towards an Urban Geopolitics. Routlede, London, 2004. 
40. Hajer M. and Rejundorp A. In Search of New Public Domain. NAi Publishers, Rotterdam, 2001.

41. Loukaitou A., Taylor B. and Fink C. Rail transit security in an international context: lessons from four cities. Urban Affairs Review, 2006, 41, No. 6, 727-748.
42. Bosher L. S., Carrillo P. M., Dainty A. R. J., Glass J. and Price A. D. F. Realising a resilient and sustainable built environment: towards a strategic agenda for the United Kingdom. Disasters: The Journal of Disaster Studies, Policy \& Management, 2007, 31, No. 3, 236-255.

\section{What do you think?}

To comment on this paper, please email up to 500 words to the editor at journals@ice.org.uk

Proceedings journals rely entirely on contributions sent in by civil engineers and related professionals, academics and students. Papers should be 2000-5000 words long, with adequate illustrations and references. Please visit www.thomastelford.com/journals for author guidelines and further details. 